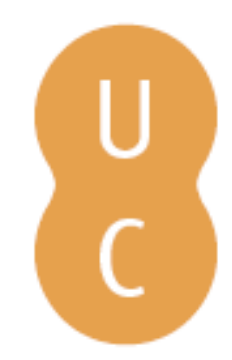

\title{
pommalina
}

\section{Leitura de Mundo e Experiências de Pensamento}

Autor(es): $\quad$ Sá Júnior, Lucrécio Araújo de

Publicado por: Imprensa da Universidade de Coimbra

URL

persistente: URI:http://hdl.handle.net/10316.2/41298

DOI: $\quad$ DOI:https://doi.org/10.14195/978989 26 1326-0_9

Accessed : $\quad$ 26-Apr-2023 06:14:05

A navegação consulta e descarregamento dos títulos inseridos nas Bibliotecas Digitais UC Digitalis, UC Pombalina e UC Impactum, pressupõem a aceitação plena e sem reservas dos Termos e Condições de Uso destas Bibliotecas Digitais, disponíveis em https://digitalis.uc.pt/pt-pt/termos.

Conforme exposto nos referidos Termos e Condições de Uso, o descarregamento de títulos de acesso restrito requer uma licença válida de autorização devendo o utilizador aceder ao(s) documento(s) a partir de um endereço de IP da instituição detentora da supramencionada licença.

Ao utilizador é apenas permitido o descarregamento para uso pessoal, pelo que o emprego do(s) título(s) descarregado(s) para outro fim, designadamente comercial, carece de autorização do respetivo autor ou editor da obra.

Na medida em que todas as obras da UC Digitalis se encontram protegidas pelo Código do Direito de Autor e Direitos Conexos e demais legislação aplicável, toda a cópia, parcial ou total, deste documento, nos casos em que é legalmente admitida, deverá conter ou fazer-se acompanhar por este aviso. 


\title{
9. LEITURA DE MUNDO E EXPERIENCIAS DE P E N S A M E N T O
}

\author{
Lucrécio Araújo de Sá Júnior 25
}

\section{Resumo}

Este trabalho objetiva discutir o uso da Leitura na escola enfocando os conceitos de autonomia e liberdade a partir do pensamento de Paulo Freire. A base teórica do estudo está na leitura do texto "O processo de alfabetização de adultos como ação cultural para a libertação" e o texto "Ação cultural e conscientização". Os dois textos fazem parte do artigo escrito em fins de 1969, em Cambridge, Estados Unidos, e publicado pela primeira vez na Harvard Educational Review, em 1970. Nossa proposta principal é observar que o pensamento de Paulo Freire deixa uma grande perspectiva conceitual e pedagógica para a formação de leitores na atualidade, uma vez que podemos transpor seus ideais para além da metodologia de alfabetização que ele propõe. Uma vez superados os problemas de alfabetização de adultos, vislumbramos com o pensamento do referido filósofo, sobretudo discutir a formação humana para uma consciência político-social, uma vez que como observa Freire (2007, p. 51)

25 Universidade Federal do Rio Grande do Norte. 
"toda prática educativa implica uma concepção de seres humanos e de mundo".

\begin{abstract}
This paper aims to discuss the use of reading in school, focusing in the concepts of autonomy and freedom in Paulo Freire's thinking. The theoretical base of the study is the reading of the text "The adult literacy process as cultural action towards freedom" and the text "Cultural action and awareness". Both texts are part of an article written in late 1969, in Cambridge, USA, and published for the first time in Harvard Educational Review, in 1970. Our main purpose is to point out that Paulo Freire's thinking gives a great conceptual and pedagogical perspective to the training of readers today, since we can implement his ideas beyond the literacy methodology that he proposes. Once overcome the adult literacy problems, we address, based on the philosopher's thinking, a discussion about the human education towards a political-social awareness, once, as Freire (2007, p. 51) says, "all educative practice implies a conception of human beings and of the world".
\end{abstract}




\section{Introdução}

Paulo Freire buscou com seu trabalho erradicar o analfabetismo, principalmente em se tratando de Jovens e Adultos, sujeitos trabalhadores em seus diversos contextos sociais e situação de vida que permaneciam marginalizados em relação à leitura e a escrita. Como sabemos, a ação de Paulo Freire estava para além de uma educação mecânica, conteúdista e bancária. Paulo Freire, enquanto educador buscou, sobretudo, dar ênfase às relações entre educador e educando e às condições de trabalho, a fim de que o processo de educação não fosse apenas uma atividade meramente utilitária ao sistema econômico dominante, mas sobretudo uma possibilidade de reflexão sobre o contexto histórico, a conjuntura política, econômica e social em que os sujeitos estão inseridos.

Do trabalho desenvolvido por Paulo Freire emergem muitas abordagens sobre a especificidade da atividade docente e as perspectivas pedagógicas da formação em todos os níveis de ensino. O presente trabalho pretende tomar parte desse debate, situando alguns temas e apresentando alguns posicionamentos que caracterizam a perspectiva política da Educação como possibilidade de desenvolvimento de autonomia e liberdade humana. O trabalho se desdobra em uma apreciação do pensamento de Paulo Freire sobre o conceito de "diálogo" e sua relação com o contexto de ensino, bem como em uma identificação dos principais objetivos e desafios colocados pela educação no ambiente escolar para o trabalho com o texto literário (Sá Júnior, 2014).

\section{A educação como possibilidade de emancipação}

Para dar início ao desenvolvimento deste estudo propomos pensar sobre o porquê da educação. Para esta questão, Paulo Freire parte 
de uma perspectiva que situa o homem no contexto da divisão do trabalho, e a partir de Platão, seu lugar de Governo. Esta posição transposta para o contexto de Democracia, deixa explícita a educação como capaz de considerar o significado global daquilo que o ser humano faz em seu cotidiano. A educação, no processo de vida social, se apresenta de tal modo que é responsável por ensinar a discutir os valores que dirigem a existência humana. A análise freireana nos faz pensar que "precisamos de educadores dialógicos" que compreendam o seu papel no percurso formativo de sujeitos capazes de se tornarem emancipados, livres e autônomos, cidadãos conscientes, e que se situem criticamente no coração de uma sociedade democrática.

Paulo Freire observa que os verdadeiros educadores são capazes de transpor através do diálogo a possibilidade de cada sujeito desvelar uma concepção de ser humano e de mundo. Assim, a educação deve ser tomada como ação orientada para a percepção crítica da realidade, sobretudo para que os sujeitos sociais se apercebam de seu papel social e de sua ação transformadora através do trabalho. Para Freire o trabalho é ação. Só através do trabalho é que o homem é capaz de se emancipar; o trabalho possibilitará o homem ao exercício da dignidade, uma vez que este estará contribuindo para a construção partilhada da sociedade. Nesse sentido, a consciência do trabalho não pode ser mecanicista, nem estar a serviço da manutenção de uma hegemonia econômica dominante, mas se faz como crítica, como decisão, valoração.

Do construto teórico observado no pensamento de Freire, é necessário que a educação esteja planejada para a superação do padrão mecanicista. Assim, se historicamente superamos o problema da alfabetização, é preciso que atualizemos o pensamento de Paulo Freire no sentido de buscarmos efetivar nas práticas pedagógicas o exercício da "palavra transformadora" do "pensamento linguagem". Se superamos o analfabetismo é necessário superarmos a visão ingênua, mecanicista; precisamos superar a educação sem 
objetivos, a educação não humanizada, superação da leitura e da escrita alienante, com pouquíssimo grau de reflexão. A escola na contemporaneidade e seus processos formativos de longa duração está condicionando os sujeitos à escritas e leituras amorfas, acríticas. A escola na atualidade está marcada por uma neutralidade política.

Para que a transformação escolar aconteça. É necessário que também ocorra a transformação nos cursos de formação de professores, a fim de que se possa ter definidas e pensadas as possibilidades para a existência de professores críticos e reflexivos, capazes de problematizar as situações vivenciadas e observadas na escola, como parte do ambiente externo que a rodeia. Em que pese a importância dessa ideia, é preciso examinar os limites e possibilidades, para que os professores formadores de professores, tenham a clareza de que tipo de educação almejamos no ambiente escolar. Que tipo de reflexões tem sido realizadas pelos educadores e educandos? As reflexões incorporam um processo de consciência das influências econômicas no processo formativo?

Como observa Paulo Freire (2007, p. 57), "analfabetos ou não, os oprimidos, enquanto classe, não superarão sua situação de explorados a não ser com a transformação radical, revolucionária, da sociedade de classes em que se encontram explorados". Vemos nesta observação que o processo de educação, como ação cultural para a libertação, é um ato de conhecimento em que os educandos assumem o papel de sujeitos cognoscentes críticos, numa atitude corajosa de desmitologização da realidade. Pensamento e linguagem neste aspecto devem ser efetivados com todo o poder que a autenticidade requer. Saber e conhecer neste sentido são consciência de si, consciência do outro, e consciência do mundo, também da conjuntura político econômica, da estrutura social e histórica, da produção de cultura e tecnologia.

$\mathrm{Na}$ atual realidade social e política, dada a superação no analfabetismo, devemos buscar efetivação do processo educativo em todos os seus níveis; principalmente na escola de educação básica 
devemos buscar efetivar a perspectiva de ação em que os sujeitos sejam conscientes da sua capacidade de criar projetos para emancipação de si mesmos na esfera pública e privada. Assim, devemos buscar a realização do processo de pensar, ler e escrever com o profundo significado de uma linguagem intencional. Uma vez aprendida a palavra, observa Paulo Freire, é preciso que se saiba "dizer a palavra". Observa ele que, um comportamento humano que envolve ação e reflexão se faz em,

Dizer a palavra, em um sentido verdadeiro, é o direito de expressar-se e expressar o mundo, de criar e recriar, de decidir, de optar. Como tal, não é o privilégio de uns poucos com que silenciam as maiorias. É exatamente por isso que, numa sociedade de classes, seja fundamental à classe dominante estimular o que vimos chamado de cultura do silêncio, em que as classes dominadas se acham seminudas ou mudas, proibidas de expressar-se autenticamente, proibidas de ser. (Freire, 2007, p. 59)

De acordo com Paulo Freire os educandos sabem que são concretos e sabem que praticam ações no mundo. No entanto, não são conscientes da potencialidade que possuem enquanto sujeitos livres e autônomos, e às vezes se tornam ambíguos porque exercitam a cultura do silêncio, porque se permitem submergir na cultura dominante que os inferioriza e aprisiona. Observa Freire que a percepção disto é indispensável aos formadores de professores. Uma vez que tal percepção nos ajuda a rejeitar o perfil que marginaliza a escola, o processo formativo, a tarefa de poder usar a palavra, de "pronunciar o mundo" livremente.

É preciso que cada vez mais possamos estar conscientes do papel social que exerce o educador, pois a ação deste deve ser sempre politizada. Todas as atitudes de pensamento, de linguagem através dos textos e demais recursos utilizados em sala de aula fazem parte 
de uma escolha ou não escolha. A educação, como um ato de conhecimento, pressupõe uma teoria do conhecimento e um método que corresponda a esta teoria. Observa Freire que, como ato de conhecimento, a educação implica a existência de dois contextos dialeticamente relacionados. Um é o contexto do autêntico diálogo entre educadores e educandos, enquanto sujeitos de conhecimento. É o contexto teórico. O outro é o contexto prático, concreto, em que os fatos se dão. Trata-se da realidade social empiricamente verificável em que os educandos estão inseridos.

Para Freire é pensando a sua ação cotidiana, em sentido cada vez mais crítico, que os educandos serão capazes de substituir a visão focalizada da realidade. Essa mudança de atitude está relacionada a duas dimensões: a dimensão pessoal e a dimensão social. Na dimensão pessoal as conquistas cognitivas mudam a índole e os sentimentos e o modo de considerar-se a si mesmo. Essa mudança produz uma nova relação com a realidade e com os outros.

\section{Ler literatura para ler o mundo}

A capacidade de ler e interpretar textos é indispensável para aquisição de novos conhecimentos e para a execução de qualquer atividade profissional. Compete, pois aos educadores a elaboração de estratégias para a melhoria do desempenho dos educandos na compreensão da realidade a sua volta. É tarefa do educador disponibilizar os instrumentos necessários para que os educandos se tornem leitores proficientes da realidade a partir do conhecimento de diferentes gêneros textuais e discursivos que circulam socialmente e nas diferentes mídias e tecnologias. Na atualidade a rapidez e o excesso de informações conduzem os sujeitos sociais a uma leitura cada vez mais superficial e aligeirada. Os educadores precisam estar cônscios dos tipos de textos e textualidades que 
utilizam, a fim de que possam descortinar o que estar por trás de suas atitudes em face da realidade cultural para assim enfrentá-la de modos diferentes.

Pensando na educação de modo geral, postulamos que é necessário que os educadores tenham bastante clareza sobre o que é feito na sala de aula, na escola, na comunidade escolar e na vida como um todo. Ao pensarmos numa didática potencializadora de uma aprendizagem significativa e libertária, a interdisciplinaridade é um importante recurso para a transposição didática. Ora, o pensamento de Paulo Freire, a parir do momento que prioriza a realidade e situações de vida dos educandos, propõe um método interdisciplinar focalizado na realidade dos alunos. O pensamento de Paulo Freire abarca as mais variadas matizes de pensamento e contribui para que os educandos não considerem o conhecimento como uma "caixinha" isolada de saberes, mas como algo capaz de contribuir para a compreensão da realidade em que se vive.

Ao falarmos do método de Paulo Freire é comum voltarmos nosso pensamento para o eixo estruturante de suas palavras geradoras. A presença de decalques neste ideário pedagógico, objetiva contextualizar a aula e fornece segurança ao educando para compreender de onde começar, para onde se vai como o saber adquirido, para onde se anda no desenrolar da metodologia de aprendizagem previamente planejada. Não esqueçamos que aprender para Paulo Freire está ligado ao processo de aprender saberes procedimentais e atitudinais (métodos, exercícios, técnicas, hábitos, disposições e valores).

Para Paulo Freire é pensando sobre sua ação cotidiana, em termos cada vez mais problematizantes da realidade, que os educandos serão capazes de substituir sua visão focalista por uma visão global. E isso poderá ser feito, do ponto de vista da teoria do conhecimento, se os alunos forem levados a assumir o dinamismo da pergunta para sua vida prática a fim de que possam fazer a decodificação de suas situações existenciais admirando-se com tudo aquilo que se 
apresenta. Para Paulo Freire, admirar-se é por-se a frente de si mesmo, é olhar para si, e também olhar para o outro e para o mundo fora da visão acostumadamente ligeira de julgar. Admirar-se é tornar o ato de conhecer como processo imanente de vida. É desenvolver a percepção do momento presente comparando-o com situações passadas e valorando a perspectiva futura. É assim, que é possível superar equívocos cometidos nas ações desempenhadas.

Nesse processo de admirar-se, na perspectiva de decodificar a realidade, os educandos poderão começar a questionar a opinião que tinham da realidade a fim de que possam substituí-la por um conhecimento cada vez mais crítico da mesma. É neste sentido que Paulo Freire enfatiza o diálogo, como possibilidade verdadeira para o acontecimento do conhecer; neste sentido é preciso que os educandos sejam levados a descobrir a sua realidade, a questionar seus atos, a sua história, seu modus vivendis, o modus operandis da sociedade em que está inserido. É preciso que sejam levados a aprender a realidade no sentido de poderem descobrir a razão de ser da mesma, "e o que a faz ser do modo que está sendo" (Freire, 2002, p. 66).

Para favorecer o ato de conhecimento, as escolas precisam levar os alunos a questionarem a sua realidade, a fim de que possam mobilizar seu pensamento no sentido de perceber aquilo sobre o qual se apropriam e se ocupam. Neste esforço, o educador estará contribuindo para engajar os educandos na problematização permanente da realidade e de sua ação nesta. Penso que estas decodificações da realidade, na escola devem ser realidades através de textos literários em que os alunos possam fazer problematizações: trazer para si a vida de personagens; transferir alguns de seus aspectos da realidade vivenciada.

Superada a ideia de analfabetismo a partir de palavras geradoras, é necessário agora formarmos leitoras a partir de textos geradores. Este conceito forjado a parir das ideias de Paulo Freire objetiva permitir a investigação do universo existencial dos educandos, do qual são 
retiradas as ideias geradoras do seu "universo mínimo". Esses textos, seguindo a perspectiva freireana devem ser escolhidos em função de:

a) Seu conteúdo pragmático, enquanto signos lingüísticos que correspondem a um entendimento comum numa comunidade, numa região, numa sociedade, a fim de que possam sensibilizar e problematizar as matizes da própria vida em sociedade, como foco prioritário na geo-história de sua formação;

b) Em função de seus interesses e escolhas políticas que devem ser questionados.

Como observa Freire, a análise das relações entre os seres humanos e o mundo leva necessariamente à reflexão sobre os valores intrínsecos à formação da personalidade. Para Freire, quanto mais a problematização avança e os seus sujeitos decodificadores se adentram na "intimidade" da questão, tanto mais vão se tornando capaz de desvendá-la.

Considerando, porém, que o ato de desvendar a realidade, indiscutivelmente importante, não significa o engajamento automático na ação transformadora da mesma, o problema que se nos apresenta é o de encontrarem cada realidade histórica, os caminhos de ida e volta entre o desvelamento da realidade e a prática dirigida no sentido de sua transformação. (Freire, 2002, p. 72)

Segundo a perspectiva freireana, a conscientização se autentica num movimento de ida e volta que é, em última análise, a unidade dialética entre prática e teoria, em que se aprende a captar a realidade e expressá-la por meio de uso da linguagem. É neste aspecto que os educandos poderão perceber a prática consciente da ação no mundo, envolvendo reflexão, intencionalidade, temporalidade e transcendência. 
Penso que o uso de gêneros ficcionais literários podem contribuir para ativar esta dimensão crítica da consciência, uma vez que a literatura está permeada de personagens cujas ações são transformadoras do mundo. Neste aspecto o uso da literatura ficcional da sala de aula poderá favorecer aos educandos a desenvolverem a capacidade de prever o resultado de sua ação, ainda antes de iniciada. Com a leitura literária, os educando poderão perceber que o mundo não é algo no qual devemos apenas nos adaptar para sobreviver, mas que enquanto seres humanos, somos produtores de cultura e modeladores de nossa própria realidade (Sá Júnior, 2014).

Como observam Pereira e Neves (2012), a capacidade de ler e interpretar textos é indispensável para a aquisição de conhecimentos e para a execução de qualquer atividade profissional. Se faz imprescindível que o aluno possa ser um leitor de sua realidade, capaz de analisar criticamente o contexto político e social do mundo em que vive. Assim, a escola deve estar atenta ao momento histórico em que os educandos estão inseridos para que possa dispor de textos e obras literárias que sejam representativos das diversas esferas sociais; textos que façam parte da cultura do aluno, em seus diversos contextos e abrangências, priorizando o estudo das artes, da história, da ciência, da publicidade, etc.

Os gêneros textuais variam de acordo com a finalidade comunicativa, a relação entre locutor e interlocutor, o veículo utilizado e o grau de formalidade. Diversos gêneros podem se formar em função de novas práticas sociais e culturais e de estruturas estabelecidas por essas práticas comunicativas. (Pereira \& Neves, 2012, p. 45)

As autoras observam que no dia a dia, o aluno deve ser estimulado a participar das aulas e expor seus pontos de vista acerca dos diferentes conteúdos estudados. Essa participação nas aulas está no âmbito da fala espontânea, que se constitui a base da interação 
humana, considerando que usamos esta fala espontânea em grande parte do dia. Para Pereira e Neves (2012) é responsabilidade da escola incentivar e desenvolver o falar do aluno nas sua relações mais importantes, como na família, na escola, nas rodas de amigos, nos transportes, nos espaços públicos, etc.

Dessa forma, o professor deve buscar ferramentas e metodologias para criar atividades que estimulem o desenvolvimento da expressão falada e também escrita, capacitando os educandos para atingir o amadurecimento intelectual. A capacidade de utilizar a linguagem oral e escrita com autonomia, com autoria, é o ponto culminante de uma aprendizagem significativa. Mas, apesar de os livros didáticos de português para os alunos da educação básica reservarem um espaço significativo à literatura, os exames nacionais ENEM e SAEB, quase não prestigiam a leitura da literatura clássica ficcional. Para Pereira e Neves (2012), esse fato cria um contraste entre a proposta das escolas e dos livros didáticos e a expectativa do aluno em relação ao exame que poderá garantir-lhe uma vaga na universidade.

Nesse sentido, Pereira e Neves (2012) chamam atenção para o ensino da literatura na escola dos dias de hoje. Para as autoras o objetivo do uso da literatura na sala de aula, é a formação de um leitor crítico, capaz de fruir o texto, de identificar o estilo do autor, de reconhecer características estéticas do período e de associá-lo ao contexto histórico-cultural em que o texto foi produzido, pois a literatura deve ser estudada, enfatizam as autoras, como expressão cultural.

O texto literário é marcado pela inter-relação entre os códigos lingüísticos, estilísticos, temático, ideológico; dessa forma, é necessário que o educando compreenda a interação entre esse conjunto de códigos, que constroem a literatura, e as outras formas de manifestação artística que se relacionam na produção e recepção de um texto. Daí também a necessidade da leitura intertextual e interdisciplinar dos textos literários com o cinema, as tradições 
populares, as artes plásticas, a fim de que na escola se possa promover o trabalho de análise da própria vida em sociedade.

A literatura brasileira, presente e passada, possui conjunto de autores que podemos chamar de clássicos pela excelência de sua linguagem literária, que formam um cânone. Entre os pensadores, Machado de Assis com seus contos e romances da última fase (Memórias Póstumas de Brás Cubas, Quincas Borba e Dom Casmurro); Graciliano Ramos com São Bernardo e Vidas Secas; Guimarães Rosa com Sagarana e Grande Sertão: Veredas; Clarice Lispector com A maçã no escuro e A hora da estrela. Na poesia, sem nos estendermos, lembremo-nos de Gonçalves Dias, Cruz e Sousa, Manuel Bandeira, Carlos Drummond de Andrade, João Cabral de Melo Neto, Ferreira Gullar. (Pereira \& Neves, 2012, p. 163)

O texto literário é uma oportunidade para que educador e educando possam refletir sobre a realidade. Os textos literários de ficção no romantismo brasileiro, podem ser bons exemplos para conhecermos a história do país. Com José de Alencar, por exemplo, em O Guarani e Iracema, obras literárias do auge do romantismo brasileiro, temos narrativas de um passado mítico e o encontro inaugural do colonizador português com o índio brasileiro. Os romances de Machado de Assis são retrato do cotidiano urbano do homem brasileiro, contextualizado no Rio de Janeiro os personagens vivenciam os conflitos da nova realidade sócio-econômica do país, após a ascensão de Dom Pedro II. Lembram Pereira e Neves (2012) que as grandes figuras do romance machadiano, Brás Cubas e Bentinho, são personagens cuja representação social é a burguesia tropical com seus agregados e escravos. Para além do nacionalismo brasileiro, é possível estudar a influência portuguesa sobre a cultura brasileira, para isso tem-se no Modernismo toda uma influência de Fernando Pessoa e seus múltiplos heterônimos. Não podemos deixar de lembrar os autores 
de literatura africana que surgem no horizonte cultural do Brasil após o movimento de independência; emergem autores como José Luandino, de Angola; José Craveirinha e Mia Couto de Moçambique; e Manuel Lopes e Germano Almeida de Cabo Verde.

Para o trabalho com o texto literário em sala de aula o professor pode propor atividades de pesquisa sobre a vida e obra dos escritores, destacando a sua contribuição para a literatura. Os Educandos a partir do estudo sobre os autores dos textos literários poderão partir para a investigação sobre os papéis sociais representados pelas personagens. O educador deverá chamar a atenção dos educandos para o ponto de vista, ou foco narrativo, utilizado pelo autor. Por exemplo, o uso do narrador personagem, que conhece toda a história e participa dela, é uma técnica de construção romanesca largamente empregada pelos escritores românticos e realistas, como Alencar e Machado de Assis. Considerando as possibilidades de reflexões oferecidas pelos textos literários podemos verificar:

a) A perspectiva de levar os educandos a conhecerem as diferenças entre língua falada e língua escrita, a fim de que possam compreender os usos da linguagens em diversas situações do cotidiano, dos contextos formais aos informais;

b) Observar as variantes regionais da língua do português brasileiro a fim de perceber a diferença entre norma idealizada e efetivamente a língua praticada, mesmo considerando o uso da linguagem falada por pessoas mais escolarizadas;

c) Observar a importância da língua para a construção da identidade nacional;

d) Observar com a realidade exposta nos textos os momentos históricos do Brasil, a diversidade étnica existente no território nacional;

e) Desenvolver um olhar crítico-reflexivo sobre si mesmo, sobre seu papel oscila, sobre suas atitudes e escolhas. 
Estes são alguns dos pontos que podem ser tocados nos estudos subjacentes a toda obra literária. A literatura brasileira possui, observam Pereira e Neves (2012), algumas constantes temáticas como, por exemplo, o sertão, o universo urbano, a questão social. É possível, nas atividades em sala de aula, propor pesquisas que aproximem autores e obras de diferentes momentos históricos e de estilos literários distintos, que abordem a mesma temática, como Alencar e Guimarães Rosa, tratando o sertão; Machado de Assis e Lygia Fagundes Teles, retratando o universo urbano; Aluisio de Azevedo e Lima Barreto, discutindo a questão social. Num mesmo núcleo temático pode-se encontrar uma diversidade de gêneros e de épocas (Pereira \& Neves, 2012).

O texto literário possui valor estético, permitindo diferentes interpretações e leituras que são veiculadas por recursos estilísticos como as figuras de linguagem. Em seus diferentes gêneros: poema, romance, conto, crônica, peça teatral a produção literária está associada com movimentos políticos, sociais e culturais; isso favorece a interpretação de que as características de um estilo e época não estão limitadas aos textos produzidos naquele momento específico, mas são atemporais, ou seja, podem manifestar-se em diversos outros momentos. Assim, os educandos, de acordo com as leituras realizadas, podem oferecer seus pontos de vistas, argumentando e expondo estratégias discursivas valendo-se da vida dos personagens e dos contextos sociais em que estes estão inseridos para pensar, ilustrar suas posições e refletir sobre a realidade vivida (Sá Júnior, 2014).

\section{Considerações finais}

Nesta perspectiva filosófica enfatizamos a educação que necessita se voltar para o mundo intencional dos seres humanos, uma vez que no processo de existência, nascimento, vida e morte não distinguem o individual do social, nem tão pouco existem fronteiras entre o 
real e o irreal metafísico. É preciso que a educação esteja atenta ao processo de construção da própria identidade dos sujeitos sociais. O conhecimento é muito valorizado no processo educacional, mas por vezes se deixa de lado a sabedoria existencial, que é particular e intransferível. Nesse aspecto, a educação deve ser um saber progressivo no sentido de proporcionar a crítica sobre a realidade a fim de que o saber que se tem dela possa ser substituído cada vez mais.

O texto literário na sala de aula. Pode possibilitar a reflexão sobre a vida em sociedade, prioritariamente sobre a construção de sua própria significação de estar no mundo. É nesse sentido que Paulo Freire observa que o ponto de partida para uma análise, tanto quanto possível sistemática, da conscientização, deve ser uma compreensão crítica dos seres humanos como existentes no mundo e com o mundo.

Somente homens e mulheres, como seres "abertos", são capazes de realizar a complexa operação de, simultaneamente, transformando o mundo através de sua ação, captar a realidade e expressá-la por meio de sua linguagem criadora. E é enquanto são capazes de tal operação, que implica em "tomar distância" do mundo, objetivando-o, que homens e mulheres se fazem seres com o mundo. Sem esta objetivação, mediante a qual igualmente se objetivam, estariam reduzidos a um puro estar no mundo, sem conhecimento de si mesmos nem do mundo. (Freire, 2002, p. 77)

$\mathrm{Na}$ abordagem freireana, existir é um modo de vida que é próprio ao ser capaz de resignificar, de transformar, de produzir, de decidir, de edificar, de criar, de recriar, de comunicar-se. De acordo com o pensamento de Paulo Freire, o domínio da existência é o domínio do trabalho, da cultura, da história e dos valores. A leitura do texto literário é capaz de possibilitar os educandos a experimentarem o pensamento de modo crítico, a fim de que possam desenvolver a consciência de e ação sobre a realidade. 


\section{Referências bibliográficas}

Freire, P. (2007). Ação Cultural para liberdade e outros ensaios. $1^{a}$. Edição. São Paulo: Paz e Terra.

Marina, J. (2009). El aprendizage de La sabiduría: aprender a vivir/aprender a convivir. Barcelona: Editorial Ariel.

Pereira, C. da C. \& Neves, J. dos S. B. (2012). Ler/Falar/Escrever. Práticas discursivas no ensino médio: uma proposta teórico-metodológica. Rio de Janeiro: Lexicon.

Pimenta, S. G. \& Lima, M. S. L.(2004). Estágio e Docência. São Paulo: Cortez.

Pimenta, S. G. \& Ghedin, E. (orgs.). (2002). O professor reflexivo no Brasil: gênese e crítica de um conceito. 2. ed. São Paulo: Cortez.

Sá Júnior, L. A. de. (2014). O ato de ler: possibilidades e perspectivas para ensino de literatura no Ensino Médio. In: SÁ JÚNIOR, L. A de \& Oliveira, A. Pereira de. (Org.) Literatura e Ensino: reflexões e propostas. Natal: EDUFRN. 